\title{
Undergraduate management students' perceptions of what makes \\ a successful virtual group
}

\section{Abstract \\ Purpose}

There are a number of factors that are essential to understanding the pedagogy, learning and knowledge requirements of developing virtual platforms for delivering effective course interaction using the World Wide Web (the web). This research focuses on webbased group work amongst undergraduate management students, during a two-year study investigating the development of virtual groups as an important problem solving and learning enhancement process.

\section{Design/Methodology/Approach}

This study is based on the identification of successful groups undertaking undergraduate management courses, where group work is a compulsory component of the course assessment. Focus groups are used to collect a broad qualitative understanding of perceptions of students in relation to success factors. Lexical analysis is then used to analyse data.

\section{Findings}

Lexical analysis provides four clear clusters that the subjects consider are essential to group learning and performance. The outcomes of the findings link directly back to the design of learning activities and the future direction of the research.

\section{Originality/Value}


Value is created as it advances use of the web from one of information dissemination to one of engagement and learning enhancement.

Keywords: Virtual groups, focus groups, lexical analysis, learning enhancement, management education, virtual learning.

\section{Introduction}

Business Schools are under increasing academic and financial pressure to grow their markets. In response to this pressure, there is an increased focus on the use of different methods of delivery. As a result of an ability to expand geographical offerings and increase flexibility, there is a particular emphasis on web-based media, which Jones et al $(1999$, p.3) state "... have an extraordinary potential to transform the educational process in the $21^{\text {st }}$ century." While the methods of dissemination are important, this research provides insights into particular aspects of the facilitation and improvement of learning through enhanced engagement in the educational processes through such media.

Within management education there is a desire to improve ability in areas such as problem solving, and creativity and innovation, while developing personal and interpersonal skills through the use of groups and group based problem solving. Organisations appear to be relying more on work teams, with an increase in multinational teams as well as teams working across geographical boundaries (Earley and Gibson, 2002; Shams and Jackson, 2006). However, the virtual learning environment created by the World Wide Web (the web), while used for the above educational aspects, is often difficult for undergraduate, and in some cases postgraduate, students to develop the levels 
of engagement required to achieve the full learning potential expected and desired. As Resnick (2002, p. 33) states, “...there is a real risk that only a small handful will be able to use the technologies fluently."

This research combines the concepts of using the web as a learning enhancement device through the application of virtual learning and the application of groups in management education at undergraduate and postgraduate levels. Here we present the findings from a two-year study that the authors have undertaken. The focus of the investigation is the undergraduate environment and its essential requirements as identified by the members of successful groups in achieving these outcomes. Through the use of focus group methodology and lexical analysis of the qualitative data gathered, four clear content areas emerge from the study that will guide further in-depth research over the following years.

\section{Background to the study}

\subsection{The e-learning environment}

The application of e-learning as a platform for improving group interaction and problem solving builds on the impact that the e-learning environment produces in general. It is argued by Horton (2000) that since the development of the alphabet, e-learning has, and will continue to have, the greatest impact on how humans will learn. This is further enhanced as technology, in its many forms, removes the barriers of time and space in the delivery of knowledge. Practitioners (e.g. Berry, 2000; Coné and Robinson, 2001; Rossett, 2002) and researchers alike (e.g. Brown and Ford, 2002; Galagan, 2000; Salas et al., 2002; Steele-Johnson and Hyde, 1997) support Horton's stance. 
While e-learning can broadly be defined as the use of computer networks to inform or instruct individuals, this research is framed in the virtual space and studies the direct interaction of learners and facilitators within this space. The focus is aligned with that defined by Rosenberg (2001) as being highly collaborative with the knowledge outcome leading to an overall improvement in performance. This research has moved from the more common asynchronous (pre-recorded) approach to that of a synchronous or live approach, which recognises that blending of the two approaches also occurs, thereby enhancing the performance and extending the delivery to different audiences.

Within the practical application of business, there has been delivery of group-based material using the synchronous approach within a global management context by Accenture (Welsh, et. al., 2003). This approach was seen as a mechanism to enhance the groups/teams based environment found in the current and future management environments where globalisation and other issues of complexity have grown in emphasis. While material has been delivered in this medium in order to enhance professional learning, there is little research in understanding the value of this style of learning and its actual outcomes in terms of effective group-based problem solving. It would be beneficial to measure, and more importantly to obtain a deeper understanding of, the learning methods that are best for the delivery of this type of learning and how to facilitate the learning interface. Within the management education context, this research focuses on group or team based problem identification, investigation and solutions within a multifaceted environment, a process often seen as central to the practice of management. The approach makes a realistic framework within which to investigate the following research question: 
What is the learner's perception of the factors required for success in the virtual space in relation to group/teams based problem identification, investigation and solving?

An added advantage of this research to the management education profession is that it assists in addressing some of the most pressing factors within business education, which Hawawini (2005) suggests are: 1) the lack of highly qualified academic staff; 2) an increasing demand for soft skills within courses while maintaining a balance of more traditionally focused analytical concepts; 3) increased financial pressures; 4) the impact of technology and communication on learning methods; 5) competitive pressures; and 6) reputation and brand development within a competitive environment.

In order to address the above situations, the business school of the future will have to progress from the face-to-face lecture/tutorial approach that is still widely used to one of a learning and knowledge network. Such progress presents a number of challenges to those receiving the education and to the professionals responsible for its delivery. The outcome of this research is the provision of a platform for understanding some of the learning issues and thereby creating possible alternatives for the long-term success of management education within a changing tertiary setting.

These alternatives would encourage engagement though the virtual environments in which many students indicate they are comfortable. By taking this approach there will be an increased use of digital and social media such as Skype, virtual interaction, face book and mobile phones. Adopting the alternatives would allow existing academic staff to have a wider spread across the student population, require an increased use of soft skills in the virtual space, and by embracing the use of communication through technology make such institutions more competitive within the undergraduate context. It is through 
understanding the requirements for this technological change, and embracing its uptake, much of Hawaini's (2005) concerns can be addressed by forward thinking academics and their institutions.

\subsection{Virtual groups or teams}

Virtual groups and teams operate without regard to geographical boundaries and traditional reliance on face-to-face meetings. The use of virtual groups and teams is very relevant to management education as argued by Olson-Buchanan et al (2007) who question "... whether graduates have the requisite skills to function effectively in a virtual environment." An example of virtual groups/teams operating is in the area of undergraduate assessment in a management program where the students are required to interact via a computer based virtual platform (CCC). Assessment required students to be in different locations and to use the platform for a majority of the group interaction. This exercise attempted to mirror realistic management activities, where the nature of the task required an integrated systems approach to professional activities, which are predominately groups or team based.

From a theoretical perspective, Ives and Jarvepaa (1995) suggest the application of team work for problem solving is more than just problem solving, as it is also a means of knowledge creation. In practical applications there are issues raised in terms of distance and its impacts on group productivity, anonymity and evaluative aspects of the process (Connolly et al., 1990; Gallupe and McKeen 1990; Jessup et al., 1990; Siegel et al., 1986,). Studies by Nuamaker et al (1991, p. 57) also suggest, “...distributed groups remain more task-focused than that proximate" which produces a number of issues when 
developing groups within the virtual learning environment. Issues relate to anonymity, the level of openness in discussion, social loafing, and other group and performance behaviours. Within, this context the following five level model proposed by McFadzean and McKenzie (2001) provides a useful starting point for the proposed study of virtual groups in the first instance as it has been previously used in this area and within a number of group contexts.

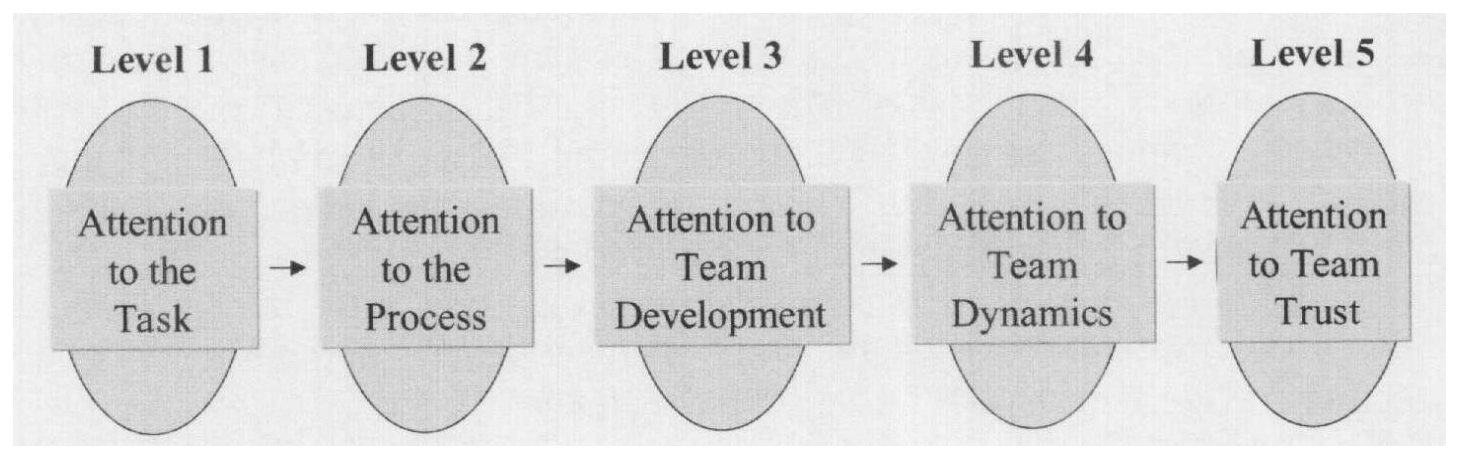

Figure 1: McFadzean Five Level Model (McFadzean and McKenzie 2001)

Further support is provided for the model with expanded group contexts by McFadzean (2002, a; 2002, b), where the stepwise relationship has been further justified. Within this justification for building effective groups there is some evidence that relationships and trust can be achieved through effective facilitation, making group trust an outcome of the group process. Birchall and Giambona (2007) and Giambona and Birchall (2008) have undertaken extensive work in the area of building virtual teams within small to medium enterprises (SMEs) as a means of achieving learning communities. While not an undergraduate university environment, it is still within the context of achieving effective virtual learning. These authors identified in their research the relevance of McFadzean and McKenzie (2001) model's focus on congruence when establishing processes and goals and the importance of a safe personal environment free 
from direct criticism. They also highlight aspects of relationship between trust and learning in the virtual space stating "...whilst systems may be designed to facilitate a diversity of learning and opportunities for knowledge sharing, the learning experience is largely in the hands of the learners so it is unpredictable as is the level of trust achieved" (Birchall and Giambona, 2007, p.119). The model provides some insight into groups, the virtual space and learning though it does not give direct insight into the introduction of virtual space into the business course environment.

There has been some initial research within the delivery of business courses, which suggests that traditional course delivery is seen as being more effective in providing knowledge and skills, than e-learning environments. However, further research suggests that there is no reduction in performance, as measured by examination, when groups use virtual delivery compared to traditional means of delivery (Lu et al., 2003, MacDonald et al., 2004; Olson, 2002; Priluch 2004).

Previous research highlights a need to gain further understanding of why certain aspects of traditional classes are preferred to material delivered within the virtual learning environment. Specifically, in this situation there is a need to understand the group requirements for successful operation in a virtual fashion. While there are some issues that relate to technology and communications, the speed and reliability of the computer interface can be controlled fully within the university environment. Research by McFarland and Hamilton (2006) in team environments indicates that the level and effectiveness of synchronous interaction is important in improving learning experiences. This outcome, in conjunction with the nature of the computer interface and methods of human facilitation, is essential to the effectiveness of the process. Therefore, there needs 
to be a greater understanding of delivery mechanisms from a human perspective if learning is to occur. Two ways of addressing this are achieved by understanding the delivery through the eyes of the student, and secondly by trialling different mechanisms to support this type of interaction such as learning centred portfolios. Learning centred portfolios in this situation represent a move away from traditional examination as assessment of the knowledge that is present. The move is to an interaction through a process where the learner is involved in a formative and summative loop where material is produced in relation to the concept under investigation, which is then evaluated (summative) and feedback received before the next formative phase. Currently, the researchers are interested in understanding the student's perception of successful virtual groups, as this will inform the following phase of the research on educational approaches that improve the value of group/team based problem solving within the virtual learning space. The emphasis at this stage is placed on the direct investigation of perception rather than introducing additional variables in the form of a portfolio.

\section{Method}

The research investigated third (final) year undergraduate students enrolled in a management major where group assessment was required. The study was further defined by narrowing it to those groups who were seen as highly successful for the following two reasons: Firstly, their overall knowledge and performance, as understood by their ability to address the academic aspects of the assessment based on their score then additionally by the creative, innovative or critical thinking approaches they were able to demonstrate. Secondly, the effectiveness of the group as assessed through the use of two mechanisms: 
1) a self-developed behavioural contract; and 2) a peer evaluation of group members. The behavioural contract consisted of the group developing its own mechanisms for achieving and managing the required behaviours within the group for the life of the virtual project. The contract was the outcome of consensus within the group and it defined the group's operational processes and consequences to the members and the group, particularly those who did not follow agreed processes. The approach required forward thinking and planning so that its components matched the realities of the group process. The peer review involved the feedback by peers provided in relation to the other group members' performance during the group activity. The adoption of these mechanisms allowed the researchers to identify groups that were academically effective and which had established goals, outcomes and the processes they applied to achieve them in terms of group effectiveness. The final outcome consisted of 12 groups that had between eight to 12 members providing 103 participants, with each study group being the basis for each of the focus groups. At a later date the same information was used to identify less effective groups on both measures and to address the factors that influenced their outcomes.

Prior to the study, none of the students had worked in the same groups before and none of the groups had used a virtual platform for remote and live (synchronistic) interactions as a major part of their meeting process. Student groups were self-selective and this occurred during the early stages of the research process. As an outcome of this process, each group developed a behavioural contract, which set the ground rules for each group. Therefore the process for managing the group was specific to each group. This was a further reason for selecting groups as it was a method of gaining insight to those who could successfully manage these and other group dynamics. Students were provided 
with training on the medium for interaction (the CCC platform) and had covered basic concepts in terms of group dynamics in other courses along with part of the course in which the study was undertaken.

A requirement of this study was to develop a platform from which an extended, further study could occur. The use of focus groups which are "...a group of individuals selected and assembled by researchers to discuss and comment upon, from personal experience, the topic that is the subject of the research" (Gibbs, 1997, p. 1), was seen as an effective mechanism of data collection. Focus groups provided additional benefit in that they are seen as including the following factors: 1) synergy because of their broader perspective; 2) snowballing via the interaction of ideas; 3) serendipity; 4) stimulation through the group process; 5) security due to less individual pressure; 6) spontaneity; 7) specialisation given the numbers per session; 8) structure as it is easier for the moderator to reintroduce a topic; 9) speed due to the numbers involved; and 10) scrutiny via observation of the process by a second party (Zikmund, 1997). Group interaction (Albrecht et al., 1993; Burns, 1989) and the replication of social forces (Krueger and Casey, 2000; Robson, 1990) are central to the benefits provided by focus groups and relevant to this stage of the research.

The groups involved in the study were brought together in a safe, confidential environment with an independent facilitator and asked to provide their reflections on what made their group work effective and successful, particularly emphasising the move towards virtual groups. Group discussions were audio recorded while a second facilitator captured additional data by observation. Observational data were used simultaneously to prompt for clarification if it was required, as well as a means of enhancing the analysis. 
Transcripts were then produced, participants were provided with the material relevant to their focus group and clarification and verification were sought in relation to the text obtained.

Each group was asked the following questions:

1. What makes you believe you might have had a really effective group/team?

2. Did you use any formal techniques to work out how you were going to manage yourselves?

3. Is there anything you would have changed in the way that you actually ran your group?

4. Was this work environment (virtual) conducive for coming together and doing group/team work, discussion/activities?

5. What do you think your colleagues need to learn or understand to make their virtual groups more effective? In other words, what advice do you have for the others?

6. What would be the one thing you would summarize that worked for you as a virtual group?

7. What would be the one thing that you'd summarize that stands out why other groups don't work?

The audiotapes of the responses obtained were then transcribed and these transcripts were entered into appropriate software for analysis.

\section{Findings}


In computer-aided lexical analysis, each word forms the unit of analysis (Krippendoff, 1980). Leximancer Version 2.25 was used to analyse the data. Leximancer's learning capability generated and put similar words into groups automatically as synonyms, then represented them as a 'concept' (Smith, 2003). A concept is a collection of words that travel together, with groups being constructed in Leximancer through the use of both implicit and explicit means. Therefore, the actual word does not have to appear in the sentence for the concept to be identified. Leximancer's output is presented visually in the form of a concept map.

The concept map contained all major concepts identified by the lexical analysis; in this case the initial number of concepts was 22. Two of these concepts were discounted and removed in generating the final map, as they did not provide value. These were 'Umm' as in a pause for thought and 'Guess' as in "I guess so," whereas the other 20 concepts were linked to information relative to students' discussion on effective virtual groups. The relative frequency of these 20 concepts is provided in Table 1. 
Table 1: Concepts and their relative frequencies

$\begin{array}{llllll}\text { Concept } & \text { Absolute } & \text { Relative } & \text { Absolute } & \text { Relative } \\ \text { Count } & \text { Count } & \text { Concept } & \text { Count } & \text { Count } \\ \underline{\text { think }} & 45 & 100 \% & \underline{\text { back }} & 10 & 22.2 \% \\ \text { group } & 40 & 88.8 \% & \underline{\text { comfortable }} & 10 & 22.2 \% \\ \text { people } & 27 & 60 \% & \underline{\text { structure }} & 9 & 20 \% \\ \text { groups } & 23 & 51.1 \% & \underline{\text { meetings }} & 9 & 20 \% \\ \underline{\text { room }} & 19 & 42.2 \% & \underline{\text { effective }} & 9 & 20 \% \\ \underline{\text { work }} & 17 & 37.7 \% & \underline{\text { wanted }} & 9 & 20 \% \\ \underline{\text { time }} & 16 & 35.5 \% & \underline{\text { person }} & 8 & 17.7 \% \\ \underline{\text { knew }} & 15 & 33.3 \% & \underline{\text { set }} & 7 & 15.5 \% \\ \underline{\text { type }} & 13 & 28.8 \% & \underline{\text { talk }} & 6 & 13.3 \% \\ \underline{\text { meeting }} & 13 & 28.8 \% & \underline{\text { computers }} & 6 & 13.3 \%\end{array}$

These 20 concepts were grouped into four major clusters, shown as Figure 2. These clusters were 'think' (which appeared as a central theme and was the highest occurring concept), group, work and comfortable. There is significant qualitative evidence (over 70 pages of concepts and co-occurrences) that describes these concepts and their relationship, however, word length makes it necessary to report only summaries in this article with a few typical examples to assist the reader's understanding. 


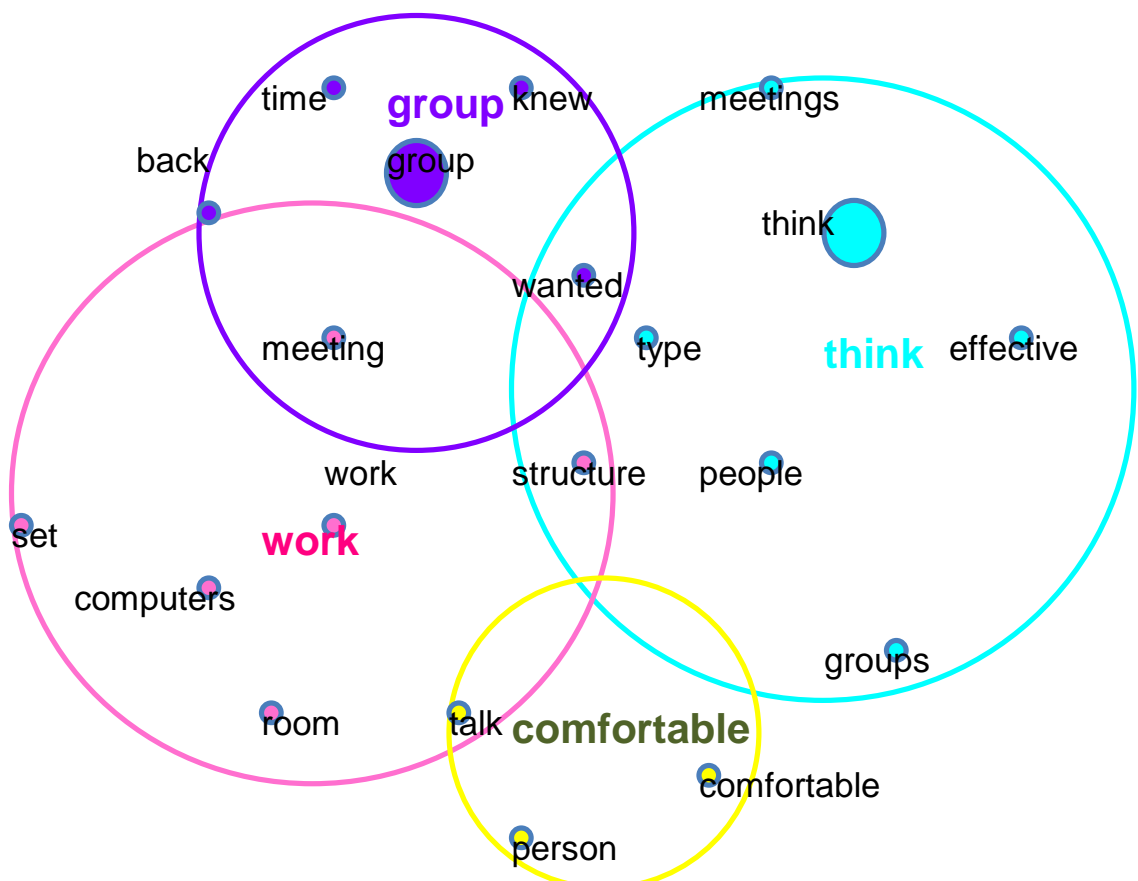

Figure 2: Concept map identifying 4 main clusters after 1000 iterations.

Through an extensive evaluation of the language used in reference to the clusters and the concepts included, the clusters in Figure 2 demonstrate the following outcomes: starting at the concept 'comfortable' there needed to be human interaction that created this feeling, it was about identifying with the 'person' and developing a rapport at this level. This is expressed by statements such as "I think you know what everybody is saying yeah it is commitment and getting everybody involved and making sure that everyone is comfortable that everyone knows what is wanted." The link between the idea of being 'comfortable' or secure in developing the group and work is 'talk'. Here the individuals were able to identify aspects of a work environment essential to the 'group'. 'Talk' or talking facilitated this in order for the participants to move towards the analytical or thinking aspects of the task required. 'Comfort' is a fit amongst the individuals who need to be achieved first. 
The 'think' cluster which houses the most frequent concept identified in the analysis (think) is formed around activities that assist in identifying and solving problems, both hard and soft. This cluster had language that included the following:

"I think too that like I said before our motivation was more out because we wanted to be there cause to the loyalty rather than as coercive fear and those types of things. We had a good structure of leadership, there was no one dominant leader although certain people talked more ahh we had a good mix of people that umm, yeah sort of everyone had their say and we were all open to that say no one was blunted."

In this case, it could be seen that the concept of 'think' is a qualifier similar to 'guess.' Further investigation highlighted that this concept has a complexity. The following four extracted comments indicate the level of mental effort that effective group members have when developing the process in the virtual space.

"one of the main things is to think about preparation"

"When you think it through its very clear with what is expected, when it is to be done"

"behavioural contracts are preferred .but you have to think them through and talk through the contents and treat the idea as a formal contract"

"when you have a group situation normally in a room they would spend 5/10 minutes talking and the last minute you go oh ok guys in the virtual space you 
cannot procrastinate as much therefore you have to think about the process and the activities and the outcomes it is just one of those things"

This demonstrates more clearly the nature of 'think' as an active rather than passive process.

Emanating from the core of this cluster there are three important concepts, these are 'type', 'people' and 'effective'. Each of these relate to the way group members think about and relate to each other and the topic or situation at hand. 'Type' refers to individual traits such as temperament and how to understand and blend these different types of temperament within the group. The concept 'people' is the macro or social content of 'person' and it relates to the interactions amongst the individuals who make up the group and develop in a fashion that builds on individuality while understanding group needs. The third concept 'effective,' relates to an effective understanding of the situation at hand and also identifies the effective skills each member had to help the thinking process and improve the outcomes. Other concepts in this cluster included: 'groups' which is thinking about groups and group management and developing plans to address issues here; whereas 'meetings' was a facilitating process to bring together the group/subgroups to identify and create relevant outcomes. The two words that link the 'think' cluster to the 'work' and 'group' clusters were the concepts 'wanted' and 'structure'. 'Structure' relates to the physical environment and daily activities within that led to the outcomes arrived at from the thinking process. Whereas 'wanted' was a concept that is aligned with the outcomes or goals that the group wished to obtain.

Moving from the 'think' to 'group' cluster through the idea or concept of 'wanted' (which uses the goals or attainments as set by the group through the thought process) we 
see some important concepts. The core of the cluster 'group' relates to understanding and working with group dynamics. Statements typical of this included the following: "the main two things that probably made us have been touched on too you know obviously group dynamics, expectations, we knew what was required umm and we were sort of going at it our way and help other people it was sort of like a loyalty and a good rapport that was created." Within and around this core are the following concepts. 'Knew' which is an extension of 'wanted' in that the group has come to identify what the desired outcomes are and how to achieve them, including the use of group dynamics to enhance the process. 'Time' is the important concept of time management and availability. This is the ability of the group to manage its processes as well as individuals meeting timelines or communicating why timelines are not met to group members. 'Back' is an important word in that it summarises the concept of feedback or going back to seek clarity emphasising the importance of understanding 'wanted', 'knew' and 'time'. The word 'meeting' relates to physically meeting and bringing the group together. This explains its position in the overlap between group and work as it is at this point that the two activities come together.

The 'work' cluster relates to the action or process to achieve the required outcomes. The typical work clustered responses included comments such as “...it's great the idea of bringing on more computers and that type of thing but there's a 30cm gap and a computer [issue raised by students when using existing university computer Labs to work across campuses on the project or for an initial set up meeting] and you can't arrange a meeting with 5 people uh one on each computer in a vertical line sorry a horizontal line ah its just ineffective cause you 
are yelling out from here and there and its just not working but um I think too really effective for this course in particular um we used a lot of statistical tools is like butchers paper and that type of thing and I know when you bought in like paper and all that you know had texta pens and that was really useful and all the diagrams and stuff that was pivotal to what we were doing cause once you have something written down you are physically involved in like manufacturing it you really get a sense of what it's all about rather than just trying to do something on the computer cause you know we are not all computer [literate]."

There are a number of clearly defined concepts here, firstly the logical links to the 'group' and 'think' clusters are the concepts of 'meeting' and 'structure' respectively. As mentioned earlier the link to the 'comfortable' cluster is the concept of 'talk'. For effective work to occur there is a need for the establishment of dialogue between group members that conveys both meaning and trust. Also a 'structure' must exist that conveys both knowledge of the issue, problem or group activity as well a structure that presents the individual aspects of the group members and how to manage these traits effectively within the group. The outcome of developing a strong group dynamic is the meeting itself. In the 'work' cluster the concepts in addition to the above are resources such as computer availability and ready access to work space, which is inductive to the process as in 'room' and 'set', which is a concept that involves a 'set' or setting of daily targets for the group to achieve. This material also relates to the initial face to face interaction, which effective groups undertook prior to going virtual as a group. This provides practical insights into the understanding of the complex understanding the group 
members gained in terms of available resources, the thinking processes of others including motivation and enthusiasm for the topic, process and outcome.

The findings in relation to the research question "What is the learner's perception of the factors required for success in the virtual space in relation to group/teams based problem identification, investigation and solving?" suggests the following:

1. That an effective approach in relation to how the group and its members think about managing both the group and its participants is as important as the thinking required in investigating the group task;

2. For this to occur there needs to be a high level of comfort amongst the group members and an effective work environment which includes sufficient resources, structure and the daily setting of targets; and

3. From the development of the interpersonal skills and this initial relationship management, there grows the development of effective group dynamics, which facilitate the meeting aspect of the work environment.

These results also suggest that while models such as McFadzean's (2001, 2002a, $2002 \mathrm{~b}$ ) are useful, the actual process is not linear as indicated in this model. The interactive nature suggested here appears to be significant in the development of virtual groups, as McFadzean's (2001, 2002a, 2002b) end phase of trust is actually a key developmental point required at a much earlier stage of the process. This is supported by Olson-Buchanan et al (2007) who state, "groups that had effectively developed into teams had shared more personal information at the beginning of the semester." It is the initial iterations between the four clusters identified in the concept map that creates this comfort level. This process appears to be driven by the high level of knowledge in terms 
of both the problem under investigation and the ability to develop interpersonal and group relationships, and the associated high level of trust.

\section{Conclusion}

This research provides a different platform for understanding the requirements of management students in terms of skill development, work environment and background preparation for developing virtual groups/teams at the undergraduate level. The interactive nature of the process identified here is different from an earlier model, which tended to be linear. The approach taken from the findings suggests that evaluating the group's process through observation and external facilitation is important along with the time and space for individuals to achieve a high level of rapport.

The implications of the findings also go further in showing important differences between personal use of virtual mediums and its application in problem solving situations. Many students indicate that they are very comfortable in environments that are virtual through the use of digital and social mediums such as face book, mobile phones and second world. When they are within the group environment and outcomes are required in relation to problem identification and solving, this is then related to a measure of performance and it is here that the face-to-face aspect still has a significant role. When face-to-face interaction is included in a way that develops trust, understanding, cohesion and communication, and sufficient resources are provided, then the use of virtual groups is enhanced. This indicates that virtual work grows with greater effectiveness

The next phase of our research is to replicate the study with postgraduate students while delving deeper into the material identified in the concept map presented as Figure 
1. The extension of the existing findings will assist in identifying mechanisms that will develop the concepts suggested by successful student groups as important to the development and running of virtual groups in a management education environment. The outcome of the larger study will be to provide an interactive learning environment via the web which assists in addressing the issues raised by Hawawini (2005) in the introduction to the paper, thereby making the web an environment for the engagement of learning rather than being just an information pipeline.

\section{References}

Ahuja, M. K. and Galvin, J. E. (2003), "Socialization in virtual teams", Journal of Management, Vol. 29, pp. 161-185

Albrecht, T. L., Johnson, G. M. and Walther, J. (1993), “Understanding communications processes in focus groups", In D. L. Morgan (Ed.), Successful Focus Groups: Advancing the State of the Art, Sage, Newbury Park, CA.

Bell, B. S. and Kozlowski, S. W. L. (2002), “A typology of virtual Teams: Implications for effective leadership", Group \& Organization Management, Vol. 27 No. 14, pp. $14-49$.

Beranek, P. M. and Martz, B. (2005), "Making virtual teams more effective: Improving relational links", Team Performance Management, Vol. 11, pp. 200-213.

Berry, J. (2000), “Traditional training fades in favour of e-learning”, Internet Week, Vol. 800, pp. 33-35. 
Birchall, D. and Giambona, G. (2007), "SME manager development in virtual learning communities and the role of trust: A conceptual study", Human Resource Development International, Vol. 10 No. 2, pp. 187-202.

Brown, K. G. and Ford, J. K. (2002), "Using computer technology in training: Building an infrastructure for learning". In K. Kraiger (Ed.), Creating, Implementing and Managing Effective Training and Development, Jossey-Bass, Mahwah N.J., pp. 192233.

Burns, C. (1989), "Individual interviews", In S. a. F. Robson, A. (Ed.), Qualitative Research in Action, Hodder and Stoughton, London, pp. 47-57.

Cascio, W. F. (2001), "Managing a virtual workplace", Academy of Management Executive, Vol. 14, pp. 81-90.

Cone, J. W. and Robinson, D. G. (2001), "The power of e-performance", Training and Development, Vol. 55 No. 8, pp. 32-41.

Connolly, T., Jessup, L. M. and Valacich, J. S. (1990), "Effects of anonymity and evaluative tone on idea generation in computer-mediated groups", Management Science, Vol. 36 No. 6, pp. 689-703.

Galagan, P. A. (2000), “The e-learning revolution”, Training and Development, Vol. 54 No. 12, pp. 24-30.

Gallupe, R. and McKeen, J. (1990), "Enhancing computer-mediated communication: an experimental investigation into the use of a group decision support system for faceto-face versus remote meetings", Information and Management, Vol. 18 No.1, pp. 113. 
Giambona, J. and Birchall, D. (2008), "Developing an Engaging Virtual Action Learning Programme for SME Managers-A UK Perspective", International Journal of Advanced Corporate Learning, Vol. 1 No. 1, pp. 9-16.

Gibbs, A. (1997), "Focus groups” [Electronic Version], Social Research Update, Vol. 19 from $\underline{\text { www.soc.surrey.ac.uk/sru/sru19.html. }}$

Hawawini, G. (2005), "The future of business schools", The Journal of Management Development, Vol. 24 No. 9, pp. 770-782.

Horton, W. (2000), Designing Web-based Training, John Wiley and Sons, New York.

Ives, B., and Jarvenpaa, S. (1996), "Will the internet revolutionise business education and research”, Sloan Management Review, Vol. 37 No. 1, pp. 33-41.

Jessup, L. M., Connolly, T. and Galegher, J. (1990), "The effect of anonymity on GDSS group process with an idea generating task”, MIS Quarterly, Vol. 14 No. 3, pp. 313321.

Kirkman, B. L., Rosen, B., Tesluk, P. E. and Gibson, C. B. (2004), “The impact of team empowerment on virtual team performance: the moderating role of face-to-face interaction”, Academy of Management Journal, Vol. 47, pp. 175-192.

Krippendoff, K. (1980), Content analysis: An introduction to its methodology, Sage, Beverly Hills, CA.

Krueger, R. A. and Casey, M. A. (2000), Focus Groups: A Practical Guide for Applied Research, Sage, Thousand Oaks, CA.

Lu, J., Yu, C. and Liu, C. (2003), "Learning Style, Learning Patterns, and Learning Performance in a Web CT-Based Course", Information and Management, Vol. 40, pp. 497-507. 
Martiens, L. L., Gilson, L. L. and Maynard, M. T. (2004), "Virtual teams: what do we know and where do go from here", Journal of Management, Vol. 30, pp. 805-835.

McDonald, M., Dom, B., and McDonald, G. (2004), A Statistical Analysis of Student Performance in Online Computer Science Courses. Paper presented at the Proceedings of the SS SIGCSE Technical Symposium on Computer Science Education, Norfolk, Virginia.

McFadzean, E. (2002a), "Developing and supporting creative problem-solving teams: Part 1-a conceptual model”, Management Decision, Vol. 40 No. 5, pp. 463-475.

McFadzean, E. (2002b), "Developing and supporting creative problem solving teams: part 2-facilitator competencies", Management Decision, Vol. 40 No. 6, pp. 537-551.

McFadzean, E. and McKenzie, J. (2001), “Facilitating virtual learning groups: A practical approach”, Journal of Management Development, Vol. 20 No. 6, pp. 470-494.

McFarland, D. and Hamilton, D. (2006), "Factors affecting student performance and satisfaction: Online versus traditional course delivery", Journal of Computer Information Systems, Winter, pp. 25-32.

Nunamaker, J. F., Dennis, A. R., Valachich, J. S., Vogel, D. R. and George, J. F. (1991), "Electronic meeting systems to support group work", Communications of the ACM, Vol. 34 No. 7, pp. 40-61.

Olson, D. (2002), “A Comparison of Online and Lecture Methods for Delivering the CS1 Course”, Journal of Computing Sciences in Colleges, Vol. 18 No. 2, pp. 57-63.

Olson-Buchanan, J. B., Rechner, P. L., Sanchez, R. J., and Schmidtke, J. M. (2007), "Utilizing virtual teams in a management principles course", Education + Training, Vol. 49 No. 5, pp. 408-423. 
Peters, L., and Karren, R. J. (2009), “An examination of the roles of trust and functional diversity on virtual team performance ratings", Group \& Organization Management, Vol. 34 No. 4, pp. 479-504.

Priluck, R. (2004), “Web-Assisted Courses for Business Education: An Examination of Two Sections of Principles of Marketing”, Journal of Marketing Education, Vol. 26 No. 22, pp. 161-173.

Robson, S. (1990), “Group discussions”, In R. Birn, P. Hague \& P. Vangelder (Eds.), A Handbook of Market Research Techniques, Kogan Page, London, pp. 261-276.

Rosenberg, M. J. (2001), E-learning: Strategies for delivering knowledge in the digital age, McGraw-Hill, New York.

Salas, E., Kosaryzycki, M. P., Burke, C. S., Fiore, S. M. and Stone, D. L. (2002), "Emerging themes in distance learning research and practice: Some food for thought”, International Journal of Management Review, Vol. 4, pp. 135-153.

Siegel, J., Dubrovsky, V., Kiesler, S., and McGuire, T. (1986), "Group processes in computer-mediated communication", Organisational Behaviour and Human Decision Process, Vol. 37 No. 2, pp. 157-187.

Smith, A. E. (2004). Leximancer Manual (Ver. 2.25 ed., pp. PDF File installed with Leximancer program).

Steele-Johnson, D., and Hyde, B. G. (1997), "Advanced technologies in training: Intelligent tutoring systems and virtual reality", In M. A. Quinones \& A. Ehrenstein (Eds.), Training for a Rapidly Changing Workplace: Applications of psychological research, American Psychological Association, Washington, D.C., pp. 225-248. 
Thompson, D. and McGregor, I. (2009), "Online self and peer assessment of groupwork", Education + Training, Vol. 51 No. 5/6, pp. 434-447.

Welsh, E., Wanberg, C., Rown, K. and Simmering, M. (2003), "E-learning: emerging uses, empirical results and future directions", International Journal of Training and Development, Vol. 7 No. 4, pp. 245 - 260.

Zikmund, W. G. (1997), Exploring Marketing Research (6th ed.), Dryden Press, Fort Worth. 